\title{
In vitro antibacterial effects of glass- ionomer cement containing ethanolic extract of propolis on Streptococcus mutans
}

\author{
Nursen Topcuoglu ${ }^{1}$ \\ Fatih Ozan² \\ Mustafa Ozyurt ${ }^{3}$ \\ Guven Kulekci ${ }^{1}$
}

\section{ABSTRACT}

Objective: The aim of this study was to evaluate the antibacterial property of glass-ionomer cement $(\mathrm{GIC})$ containing propolis against Streptococcus mutans and its effect on the in vitro S. mutans biofilm formation.

Methods: Ethanolic extract of propolis (EEP) was prepared at two concentrations as 25 and $50 \%$. Three different experimental GIC disks were prepared using pure liquid and liquid solutions diluted with 25 and 50 percent of EEP concentrations. Minimum inhibitory concentration (MIC) of EEP on the growth of $S$. mutans ATCC 25175 was determined by using agar dilution method. Agar diffusion test and an in vitro S. mutans biofilm assay for GIC disks with and without EEP were performed.

Results: MIC values of Turkish propolis for S. mutans ATCC 25175 was found as $25 \mu \mathrm{g} / \mathrm{mL}$. Experimental GICs containing propolis exhibited inhibition zones and their dry biofilm weights were less than the pure GIC. The bacterial density was lower in the GIC containing 50\% EEP.

Conclusions: A distinct antibacterial and antibiofilm efficacy of propolis containing GIC on S. mutans has been observed. Although further research is needed to show clinical results, antibacterial GIC containing propolis would be a promising material for restoration. (Eur J Dent 2012;6:428-433)

Key words: Propolis; Streptococcus mutans; glass-ionomer cement; biofilm formation; antibacterial effect

1 Department of Microbiology, Faculty of Dentistry, Istanbul University, Istanbul, TURKIYE

2 Department of Oral and Maxillofacial Surgery, Faculty of Dentistry, Abant Izzet Baysal University, Bolu, TURKIYE

3 Department of Microbiology and Clinical Microbiology, Gülhane Military Medical Academy, Haydarpasa Training Hospital, Istanbul, TURKIYE

Corresponding author: Dr. Nursen Topcuoglu Istanbul Universitesi, Dishekimligi Fakultesi, Mikrobiyoloji Bilim Dalı, 34093, Capa, Istanbul, TURKIYE Tel/Fax: +90 2124142595

Email: nursentopcuogludyahoo.com

\section{INTRODUCTION}

Over the last few decades, a worldwide increase has been observed in the use of natural products for pharmacological purposes. Propolis, which is a natural product widely consumed in the folk medicine since ancient times, is a serious candidate to be added to topical formulations due to its antioxidant properties. ${ }^{1}$ Besides antioxidant activity, epidemiological studies have also detected that propolis has many pharmacological prop- 
erties, such as antibacterial, antifungal, antiviral, antitumor and anti-inflammatory among others. ${ }^{2,3}$ In addition, this material is still used as a remedy in modern medicine due to a general "back to nature trend".

The antibacterial and antifungal properties of propolis have been extensively investigated and, although its chemical composition is linked to the phytogeographic origin, the activity of bee glue has always been reported. ${ }^{4}$ Propolis may act against a wide range of bacteria, fungi, yeasts and viruses. ${ }^{2,4}$. The antimicrobial properties of this mixture of natural substances are mainly attributed to the flavonone pinocembrin, to the flavonol galangin and to the caffeic acid phenethyl ester, with a mechanism of action probably based on the inhibition of bacterial RNA-polymerase. ${ }^{5}$

Although propolis has shown variable activity against different bacteria and there are many products containing propolis on the world market such as ethanol extracts, toothpastes and mouth rinses, few studies have been made for the antibacterial activity of propolis on oral microorganisms. ${ }^{6,7}$ Recent studies have shown the anti-caries potential of propolis. ${ }^{7-9}$ Propolis samples reduced the incidence of caries and dental plaque accumulation in vivo. ${ }^{9,10}$ Two action mechanisms have been associated with the anti-caries/anti-plaque properties of propolis: (i) antimicrobial activity against cariogenic bacteria (such as Streptococcus mutans and Streptococcus sobrinus), and (ii) inhibition of glucosyltransferase enzymes (GTFs) activity. ${ }^{10,11}$

The dental biofilm formation on tooth surfaces is a prerequisite for development of both dental caries and periodontal disease. The level of mutans streptococci ( $S$. mutans and $S$. sobrinus) in dental biofilm is associated with caries development. ${ }^{12}$ Caries is one of the primary causes of cast restoration failure, so an ideal luting agent would actively prevent caries at the restoration-tooth interface. The popularity of the glass ionomer luting cements is undoubtedly due to the fluoride release associated with these materials and the presumed benefit of reduced caries. ${ }^{13}$ Glass ionomer cement has been shown to increase the fluoride ion concentration in the saliva in the short-term, in vivo. ${ }^{14}$ When used as a restorative material, both conventional and the resin-modified glass ionomers have been shown in vitro to reduce artificial caries ${ }^{15}$ and in vivo to remineralize carious lesions ${ }^{16}$ and to enhance fluoride uptake by underlying dentin. ${ }^{17}$ Under these circumstances, we hypothesize that propolis, a well known anticariogenic material, could augment the anticariogenic properties of GIC. The aims of the present study were to investigate: (i) antibacterial effect of Turkish propolis on S. mutans; (ii) antibacterial efficacy of GIC containing propolis on $S$. mutans and (iii) effect of GIC containing propolis on $S$. mutans biofilm formation.

\section{MATERIAL AND METHODS}

Preparation of Ethanolic Extract of Propolis

Propolis samples were produced by honeybees (Apis mellifera L.) in the region of Yomra, Trabzon, Turkey, rich in Picea orientalis, Fagus orientalis, Castanes sativa, Rhodddendron ponticum, Rhododendron luteum, Rubus caucasicus. ${ }^{18}$ Propolis was provided by Trabzon Agricultural Development Cooperative. Hand collected propolis were kept desiccated and in the dark up to their processing. The samples were grinded (Ultra-Centrifugal Mill ZM 200, Retsch GmbH, Germanyl and bottled in 10 $\mathrm{g}$ portions. They were then dissolved in $20 \mathrm{~mL}$ of ethanol $(70 \%, w / v)$ by magnetic mixer for $48 \mathrm{~h}$ at room temperature. Lastly, rough particles were removed from propolis extract by filter.

\section{Bacterial Strain and Inoculum Preperation}

Streptococcus mutans ATCC 25175 type strain was used throughout the study. Bacteria were cultured overnight at $37^{\circ} \mathrm{C}$ in the Brain Heart Infusion Broth (BHI, Merck KGaA 64271 Darmstadt, Germanyl and used as inoculum. The turbidity of the suspension was adjusted to the McFarland 0.5 turbidity standard (Densimat, BioMerieux, France).

Determination of the Minimal Inhibitory Concentration (MIC)

The agar dilution method was used as recommended by the Clinical and Laboratory Standards Institute. ${ }^{19}$ Serial two-fold dilutions of EEP were prepared in Mueller-Hinton agar (MHA, Oxoid Ltd, Basingstone, Hempshire, UKJ supplemented with $5 \%$ defibrinated sheep blood. Agar dilutions ranged from 0.1 to $50 \mu \mathrm{g} / \mathrm{mL}$. Each antimicrobial test was also re-performed with plates containing the culture medium plus ethanol as solvent control. Each plate was then inoculated with a multipoint inoculating device (Steers replicator), which delivered a final inoculum of approximately $10^{5} \mathrm{CFU}$ per spot. The inoculum size was verified 
by plating serial dilutions of the inoculum and performing colony counts. All experiments were performed in duplicate while the MIC of EEP was determined.

\section{Preparation of GIC Containing Propolis}

The conventional GIC (Kavitan Pro, SpofaDental, Czech Republic) was used in this study. The test materials were: (i) GIC (Powder ${ }^{\text {GIC }}$ : Liquid ${ }^{\text {GIC }}$ ratio=1:1), (ii) 25\% EEP added GIC (PGIC: LGIC:LEEP ratio $=1: 0.75: 0.25$ ) and (iii) $50 \%$ EEP added GIC (PIC: LGIC:LEEP ratio=1:0.5:0.5). EEP was added after mixing powder and liquid of GIC. After mixing the powder and liquid of each cement, pastes were put into cylindrical molds $110 \mathrm{~mm}$ in diameter and $2 \mathrm{~mm}$ thickness), and the upper surface was flattened by pressing down with a glass slide. At $230 \mathrm{C}$ and $50 \%$ humidity, a Vickers needle $(300 \mathrm{~g}, 1.12$ $\mathrm{mm}$ in diameter) was placed onto the surface of the cement every $15 \mathrm{~s}$, and the surface was examined for any imprint left by the needle. Tests were repeated three times for each material.

\section{Agar Disk Diffusion Test}

The GIC disks were placed onto a MHA supplemented with 5\% defibrinated sheep blood agar plate and inoculated with $0.1 \mathrm{~mL}$ of inoculum. Plates were incubated at $37^{\circ} \mathrm{C}$ for $48 \mathrm{~h}$, and diameters of inhibition zones produced around specimens were measured using a digital caliper (Mitsutoyo, Tokyo, Japan) at three different points. Sizes of inhibition zones were calculated by subtracting the diameter of the specimen $(10 \mathrm{~mm})$ from the average of the three halo measurements. The procedure was modified from Takahashi et al. ${ }^{20}$ Tests were repeated three times for each material.

\section{In vitro $S$. mutans Biofilm Formation Assay}

Bacterial Culture: The stock culture was prepared in $60 \mathrm{~mL}$ Tripticase Soy Broth (Merck KGaA 64271 Darmstadt, Germanyl supplemented with $5 \%$ (w/v) sucrose. S. mutans ATCC 25175 type strain concentration of the suspension was determined as $1 \times 10^{5} \mathrm{cfu} / \mathrm{mL}$.

Processed Saliva: Unstimulated whole human saliva was used to coat the cement disks. The saliva was collected from the same person and stored at $-20^{\circ} \mathrm{C}$ before preparation. The saliva was centrifuged at $12.000 x g$ for 15 minutes. The saliva su- pernatants were decanted, treated at $60^{\circ} \mathrm{C}$ for 30 minutes and filtered by passage through a $0.2-\mu \mathrm{m}$ cellulose acetate membrane filter. ${ }^{21}$ The efficacy of filtration was assessed by culture methods.

Biofilm Formation: To allow the formation of salivary pellicle, each disk was placed in sterile plastic Petri dishes containing the processed saliva and incubated by shaking at $37^{\circ} \mathrm{C}$ for one hour. The pellicle-coated disks were then rinsed twice in sterile PBS. The disks were placed in Petri dishes containing $20 \mathrm{~mL}$ of the stock culture and incubated in $5 \% \mathrm{CO}_{2}$ at $37^{\circ} \mathrm{C}$ for 42 hours. The nonadherent cells were removed by washing the disks with sterile saline solution. To collect the biofilm, the deposits were carefully removed with sterile scalpels.

Assessment: To measure the dry biofilm weight (biomass), the collected biofilm was placed on the pre-weighed glass microcoverslips. The final weight was recorded after incubation at $60^{\circ} \mathrm{C}$ for 5 minutes. The dry weight was obtained by subtracting the weight of coverslip from the final weight.

To measure the number of viable bacteria, the collected biofilm was suspended in $4 \mathrm{~mL} 0.1 \mathrm{~N}$ $\mathrm{NaOH}$. The suspension was vortexed for two minutes and sonificated for one minute. The optical density of the biofilm was determined by a spectrophotometer (Pharmacia LKB-Ultrapec II, UK) at $640 \mathrm{~nm}$.

\section{Statistical Analysis}

Statistical analysis was performed by Kruskal - Wallis test, at 95\% confidence level using SPSS 13.0 for Windows (SPSS Inc., Chicago, IL, USA).

\section{RESULTS}

The MIC value of the EEP was found as $25 \mu \mathrm{g} /$ $\mathrm{mL}$. According to disk diffusion test results, the experimental GICs containing EEP exhibited inhibition zones (Table 1). The inhibition zone sizes were not dependent upon the concentration of propolis. The pure conventional GIC did not show any antibacterial efficacy against $S$. mutans.

According to the in vitro biofilm formation assay, the experimental GICs containing EEP developed less biomass (dry-weight) on their surface than the conventional GIC $(P<.001)$. The mean biomass amount of biofilm formed on the $50 \%$ EEP added GIC was lower than the $25 \%$ EEP, but the difference was not statistically significant (Table 2). Ac- 
cording to the optical density measurement of the formatted biofilm, the number of viable bacteria was lower in the GIC containing 50\% EEP than the $25 \%$ and the conventional GIC $(P<.001)$ (Table 3). As can be seen in Table 3, the mean bacteria count in the biofilm on the $25 \%$ EEP added GIC was lower than the conventional GIC but the difference was not statistically significant.

\section{DISCUSSION}

GICs are capable of releasing fluoride, which contributes to some reduction in the number of residual bacteria in cavities ${ }^{6,7,17}$ as well as remineralization of softened dentin. ${ }^{22-25}$ Several attempts in developing GICs with antibacterial effects by the addition of antibacterial solutions such as chlorhexidine ( $\mathrm{CHX}$ ) have been reported. ${ }^{25-30}$ With regard to these studies, we decided to use EEP, which showed remarkable antimicrobial activities against several oral microorganisms such as $m u$ tans streptococci in recent studies. 7,8,11,31

Previous studies using conventional GICs demonstrated conflicting results about antibacterial effects observed by the addition of CHX. Some of the studies reported that antimicrobial activity was dependent upon the concentration of disinfectant added to GICs, ${ }^{25,27,30}$ and others indicated no doseresponse effects. ${ }^{26}$ Beside its antimicrobial activity, propolis is considered to be safe in low doses. The cytotoxicity tests have showed that the propolis solutions, even the propolis used in our study, are safe for gingival fibroblasts. ${ }^{32}$ The chemical composition of propolis is complex and highly variable depending on its geographical origin. There are several studies on antibacterial activity of Turkish propolis. ${ }^{33-36}$ The antimicrobial assays in this study demonstrated that the propolis collected from Trabzon/ Turkey has significant activity against $S$. mutans growth, showing a MIC value of $25 \mu \mathrm{g} / \mathrm{mL}$. EEP should be kept as low as possible, as the EEP does not contribute to the formation of the glass ionomer network, and therefore, high amounts of EEP would weaken the scaffold and compromise the physical properties of the antibacterial glass ionomer. According to disk diffusion test, we found that sizes of inhibition zones produced against $S$. mutans were not dependent upon the concentration of EEP, which means that antibacterial activities were not effectively enhanced by increasing concentrations of the agent. So it would be more appropriate to use 25\% EEP addition for development in antibacterial GICs.

Bacterial adherence to tooth and restoration surface is a very important stage in the pathogenesis of dental caries and soft tissue inflammations. The adherence mechanism of bacteria to the tooth

Table 1. The inhibition zone diameters of the GIC disks (mm).

\begin{tabular}{lccc}
\hline GIC type & Control & $25 \%$ EEP & $50 \%$ EEP \\
\hline $\mathrm{n}$ & 7 & 7 & 7 \\
Mean & 0,3 & 0,7 & 0,8 \\
Standard Deviation & 0,1 & 0,1 & 0,1 \\
Median & 0,3 & $0,7^{* * *}$ & $0,8^{* * *}$ \\
\hline
\end{tabular}

***Statistically significant $(\mathrm{P}<.001)$

Table 2. The dry biofilm weights of the GIC disks (mg).

\begin{tabular}{lccc}
\hline GIC type & Control & $25 \%$ EEP & $50 \%$ EEP \\
\hline $\mathrm{n}$ & 13 & 14 & 14 \\
Mean & 0,5846 & 0,2429 & 0,1643 \\
Standard Deviation & 0,3262 & 0,1555 & 0,1336 \\
Median & 0,5 & $0,2^{* * *}$ & $0,2^{* * *}$ \\
\hline
\end{tabular}

***Statistically significant $(\mathrm{P}<$.001)

Table 3. The optical densities of the biofilms $\left(0 D_{640}\right)$.

\begin{tabular}{lccc}
\hline GIC type & Control & $25 \%$ EEP & $50 \%$ EEP \\
\hline $\mathrm{n}$ & 13 & 14 & 15 \\
Mean & 0,028 & 0,018 & 0,01 \\
Standard Deviation & 0,016 & 0,007 & 0,008 \\
Median & 0,026 & 0,0175 & $0,009 * * *$ \\
\hline
\end{tabular}

***Statistically significant $(\mathrm{P}<.001)$ 
surface occurs with the formation of acquired salivary pellicle on the surface and adherence of bacteria the acquired pellicle. ${ }^{37} \mathrm{~A}$ sucrose-mediated mechanism is a main route that facilitates bacterial adherence to surfaces. S. mutans is capable of synthesizing mainly glucans from sucrose, which promotes a high adhesion and eventually contributes to the formation of dental biofilm. ${ }^{12}$ Because of the fact that the bacteria in biofilms are more resistant than their planktonic forms, the MIC does not provide information on the efficacy of antimicrobial agents against infections involving biofilms. In vitro biofilm assays can easily be used as a relevant model for testing the antiplaque properties of the oral restorative materials.

Duarte et $\mathrm{al}^{31}$ showed that subinhibitory concentration of EEP was used to evaluate its action on biofilm formation. According to our biofilm formation assay, the GICs containing EEP developed less biomass on their surface than the conventional GIC. Although the dry biofilm weights were not significantly different on each EEP concentration, the bacterial density was lower in the GIC containing 50\% EEP. The result means the concentration is important in terms of the bacterial load on dental biofilm. In general, GICs containing EEP with each concentration showed a potential antibacterial and anti-GTFs activity in vitro, but more EEP concentration is essential to reduce $S$. mutans in biofilms.

EEP solutions have been widely used commercially on the market as toothpaste, mouth wash etc. However, it is still an unofficial drug in pharmacy. A further step should be taken to verify if a sufficient dose to kill the target microorganisms can be reached within the oral cavity, without causing major local or systemic adverse effects. Even though we studied on the cariogenic microorganism, $S$. mutans, more studies with other bacterial strains which take place for the dental biofilm formation are still needed. The effective antimicrobial activity of propolis gives hope in the treatment of oral cavity diseases.

\section{CONCLUSION}

This is the first report that evaluated antibacterial efficacy of propolis containing GIC on S. mutans. By the results of this preliminary study, it can be concluded that GIC containing propolis would be a promising material for restoration. Reduction in bacterial counts obtained by placing GIC in a cavity probably due to the release of fluoride, is not reliable; therefore, antibacterial GICs containing propolis provides an alternative approach. However, further studies should be performed on its physicochemical aspects to know how the presence of EEP interferes with the mechanical and adhesive properties of GIC.

\section{REFERENCES}

1. Kumazawa S, Hamasaka T, Nakayama T. Antioxidant activity of propolis of various geographic origins. Food Chem 2004:84:329-339.

2. Kujumgiev A, Tsvetkova I, Serkedjieva Y, Bankova V, Chistov R, Popov S. Antibacterial, antifungal and antiviral activity of propolis of different geographic origin. J Ethnopharmacol 1999;64:235-240.

3. Russo A, Cardile V, Sanchez F, Troncoso N, Vanella A, Garbarion JA. Chilean propolis: antioxidant activity and antiproliferative action in human tumor cell lines. Life Sci 2004;76:545-558.

4. Drago L, Mombelli B, De Vecchi E, Fassina MC, Tocalli L, Gismondo MR. In vitro antimicrobial activity of propolis drug extract. J Chemother 2000;12:390-395.

5. Takaisi-Kikuni NB, Schilcher H. Electron microscopic and microcalorimetric investigations of the possible mechanism of the antibacterial action of a defined propolis provenance. Planta Med 1994;60:222-227.

6. Santos FA, Bastos EM, Uzeda M, Carvalho MA, Farias LM, Moreira ES, Braga FC. Antibacterial activity of Brazilian propolis and fractions against oral anaerobic bacteria. $J$ Ethnopharmacol 2002;80:1-7.

7. Park YK, Koo H, Abreu JA, Ikegaki M, Cury JA, Rosalen PL. Antimicrobial activity of propolis on oral microorganisms. Current Microbiology 1998;36:24-28.

8. Koo H, Rosalen PL, Cury JA, Ambrosano GM, Murata RM, Yatsuda R, Ikegaki M, Alencar SM, Park YK. Effect of a new variety of Apis mellifera propolis on mutans streptococci. Current Microbiology 2000;41:192-196.

9. Koo H, Rosalen PL, Cury JA, Park YK, Ikegaki M, Sattler A. Effect of Apis mellifera propolis from two Brazilian regions on caries development in desalivated rats. Caries Res 1999;33:393-400.

10. Koo H, Pearson SK, Scott-Anne K, Abranches J, Cury JA, Rosalen PL, Park YK, Marquis RE, Bowen WH. Effects of apigenin and $t t$-farnesol on glucosyltransferase activity, biofilm viability and caries development in rats. Oral Microbiol Immunol.2002;17:337-343. 
11. Liberio SA, Pereira AL, Araujo MJ, Dutra RP, Nascimento FR, Monteiro-Neto V, Ribeiro MN, Gonçalves AG, Guerra $\mathrm{RN}$. The potential use of propolis as a cariostatic agent and its actions on mutans group streptococci. J Ethnopharmacol $2009 ; 125: 1-9$

12. Marsh P, Martin MV. Oral Microbiology. Oxford: Wright, 1999.

13. Muzynski BL, Greener E, Jameson L, Malone WF. Fluoride release from glass ionomers used as luting agents. J Prosthet Dent 1988;60:41-44.

14. Rezk-Lega F, Ogaard B, Rolla G. Availability of fluoride from glassionomer luting cements in human saliva. Scand $J$ Dent Res 1991;99:60-63.

15. Dunne SM, Goolnik JS, Millar BJ, Seddon RP. Caries inhibition by a resin-modified and a conventional glass ionomer cement, in vitro. J Dent 1996;24:91-94.

16. ten Cate JM, van Duinen RN. Hypermineralization of dentinal lesions adjacent to glass-ionomer cement restorations. J Dent Res 1995;74:1266-1271.

17. Mukai M, Ikeda M, Yanagihara T, Hara G, Kato K, Nakagaki $H$, Robinson $C$. Fluoride uptake in human dentine from glass-ionomer cement in vivo. Arch Oral Biol 1993;38:10931098.

18. Davis PH. Flora of Turkey and East Aegean Islands. Edinburgh: Edinburgh University Press, 1985.

19. Clinical and Laboratory Standards Institute. Methods for Dilution Antimicrobial Susceptibility Tests for Bacteria that Grow Aerobically. Approved standard M7-A7, Pennsylvania: CLSI document; 2006.

20. Takahashi Y, Imazato S, Kaneshiro AV, Ebisu S, Frencken JE, Tay FR. Antibacterial effects and physical properties of glass-ionomer cements containing chlorhexidine for the ART approach. Dent Mater 2006;22:647-652.

21. Sermet B, Deger S, Balkaya MC, Kaya D, Kulekci G. The effect of different dental porcelain surface treatments on plaque formation. Key Engineering Materials 2004;264268.

22. Herrera M, Castillo A, Baca P, Carrion P. Antibacterial activity of glass-ionomer restorative cements exposed to cavity-producing microorganisms. Oper Dent 1999;24:286-291.

23. Herrera M, Castillo A, Bravo M, Liebana J, Carrion P. An tibacterial activity of resin adhesives, glass ionomer and resin-modified glass ionomer cements and a compomer in contact with dentin caries samples. Oper Dent 2000;25:265269.

24. Massara ML, Alves JB, Brandao PR. Atraumatic restorative treatment: clinical, ultrastructural and chemical analysis. Caries Res 2002;36:430-436.
25. Türkün LS, Türkün $M$, Ertuğrul $F$, Ateș $M$, Brugger $S$. Long-term antibacterial effects and physical properties of chlorhexidine-containing glass ionomer cement. $J$ Esthet Restor Dent 2008;20:29-45.

26. Jedrychowski JR, Caputo AA, Kerper S. Antibacterial and mechanical properties of restorative materials combined with chlorhexidines. J Oral Rehabil 1983;10:373-381.

27. Ribeiro J, Ericson D. In vitro antibacterial effect of chlorhexidine added to glass-ionomer cements. Scand J Dent Res 1991;99: 533-540.

28. Sanders BJ, Gregory RL, Moore K, Avery DR. Antibacterial and physical properties of resin modified glass-ionomers combined with chlorhexidine. J Oral Rehabil 2002;29:553558.

29. Frencken JE, Imazato S, Toi C, Mulder J, Mickenautsch S, Takahashi Y, Ebisu S. Antibacterial effects of chlorhexidine containing glass ionomer cement in vivo A pilot study. Caries Res 2007;41:102-107.

30. Deepalakshmi M, Poorni S, Miglani R, Rajamani I, Ramachandran S. Evaluation of the antibacterial and physical properties of glass ionomer cements containing chlorhexidine and cetrimide: an in-vitro study. Indian $J$ Dent Res 2010;21:552-556.

31. Duarte S, Rosalen PL, Hayacibara MF, Cury JA, Bowen WH, Marquis RE, Rehder VL, Sartoratto A, Ikegaki M, Koo H. The influence of a novel propolis on mutans streptococci biofilms and caries development in rats. Arch Oral Biol $2006 ; 51: 15-22$

32. Özan F, Sümer Z, Polat ZA, Er K, Özan U, Değer H. Effect of propolis containing mouthrinse on oral microorganisms and human gingival fibroblasts. Eur J Dent 2007;1:195-201.

33. Kartal M, Yildiz S, Kaya S, Kurucu S, Topcu G. Antimicrobial activity of propolis samples from two different regions of Anatolia. J Ethnopharmacol 2003;86:69-73.

34. Silici S, Kutluca S. Chemical composition and antibacterial activity of propolis collected by three different races of honeybees in the same region. J Ethnopharmacol 2005;99:6973.

35. Sonmez S, Kirilmaz L, Yucesoy M, Yucel B, Yilmaz B. The effects of bee propolis on oral pathogens and human gingival fibroblasts. J Ethnopharmacol 2005;102:71-76.

36. Uzel A, Sorkun K, Oncag O, Cogulu D, Gencay O, Salih B. Chemical compositions and antimicrobial activities of four different Anatolian propolis samples. Microbiol Res 2005;160:189-195.

37. Gibbsons RJ, Houte J. On the formation of dental plaques. J Periodontol 1973;44:347-360. 